\title{
Body mass index and the risk of postoperative cerebrospinal fluid leak following transsphenoidal surgery in an Asian population
}

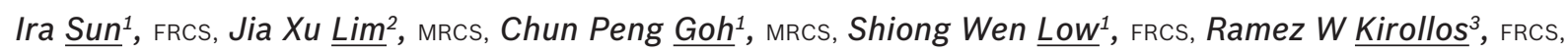
Chuen Seng $\underline{T a n}^{4}$, PhD, Sein $\underline{\underline{L w i n}}{ }^{2}$, FRCS, Tseng Tsai ${\underline{Y e 0^{2}}}^{2}$, FRACS

\begin{abstract}
INTRODUCTION Postoperative cerebrospinal fluid (CSF) leak is a serious complication following transsphenoidal surgery for which elevated body mass index (BMI) has been implicated as a risk factor, albeit only in two recent North American studies. Given the paucity of evidence, we sought to determine if this association holds true in an Asian population, where the BMI criteria for obesity differ from the international standard.

METHODS A retrospective study of 119 patients who underwent 123 transsphenoidal procedures for sellar lesions between May 2000 and May 2012 was conducted. Univariate and multivariate logistic regression analyses were performed to investigate the impact of elevated BMI and other risk factors on postoperative CSF leak.

RESULTS $10(8.1 \%)$ procedures in ten patients were complicated by postoperative CSF leak. The median BMI of patients with postoperative leak following transsphenoidal procedures was significantly higher than that of patients without postoperative CSF leak $\left(27.0 \mathrm{~kg} / \mathrm{m}^{2} \mathrm{vs} .24 .6 \mathrm{~kg} / \mathrm{m}^{2} ; \mathrm{p}=0.018\right)$. Patients categorised as either moderate or high risk under the Asian BMI classification were more likely to suffer from a postoperative leak $(p=0.030)$. Repeat procedures were also found to be significantly associated with postoperative CSF leak ( $p=0.041)$.

CONCLUSION Elevated BMI is predictive of postoperative CSF leak following transsphenoidal procedures, even in an Asian population, where the definition of obesity differs from international standards. Thus, BMI should be considered in the clinical decision-making process prior to such procedures.
\end{abstract}

Keywords: Asian, body mass index, cerebrospinal fluid leak, transsphenoidal surgery

\section{INTRODUCTION}

Postoperative cerebrospinal fluid (CSF) leak is a well-known complication following transsphenoidal surgery for sellar lesions, with a reported incidence in the range of $8.6 \%-15.9 \% .^{(1-4)}$ Its occurrence may result in meningitis, and prolonged treatment or reparative surgery are required in some patients.

Obesity is increasingly prevalent in the world today. This phenomenon holds true in Singapore as well. An association between elevated body mass index (BMI) and the occurrence of postoperative CSF leak has been suggested, but only recently and in just two studies, ${ }^{(4,5)}$ both of which had North American populations. We sought to investigate whether this relationship held true in our local multiracial Asian population when using Asian-specific criteria for BMI that were adopted by the medical practice in Singapore.

\section{METHODS}

All 147 patients who underwent 151 transsphenoidal procedures for sellar lesions at the Department of General Surgery, Ng Teng Fong General Hospital, Singapore, between 1 May 2000 and 31 May 2012 were eligible for study. Patients with incomplete data sets, insufficient anthropometric data and those who underwent surgery for an extrasellar pathology were excluded (Fig. 1). 119 patients who underwent a total of 123 procedures were included in the final analysis.
The study was approved by the hospital institutional review board. Both inpatient and outpatient medical records were retrospectively reviewed. Patient demographics and anthropometric data were recorded. Patients were categorised based on both the World Health Organization (WHO) international and Asian BMI classifications (Fig. 2). BMI data was further stratified to create three- and two-tiered classifications. In the three-tiered classification, patients who were underweight or normal (at low risk) were categorised as 'acceptable' and were compared with patients who were overweight and obese (at moderate risk and high risk, respectively) according to the Asian BMI criteria. In the two-tiered classification, overweight and obese patients comprised one group that was compared to the acceptable group, which included underweight and normalweight patients.

Histopathological diagnoses, methods of sellar repair or reconstruction, and data on intraoperative and postoperative CSF leaks were recorded. The occurrence of intraoperative leaks was determined by reviewing patients' operative records. Postoperative leak was determined as the presence of CSF rhinorrhoea on clinical examination following surgery.

The surgeries were performed by eight different surgeons at our institution. Surgeons were free to choose the method of initial access toward the sphenoid sinus - either transnasal or 


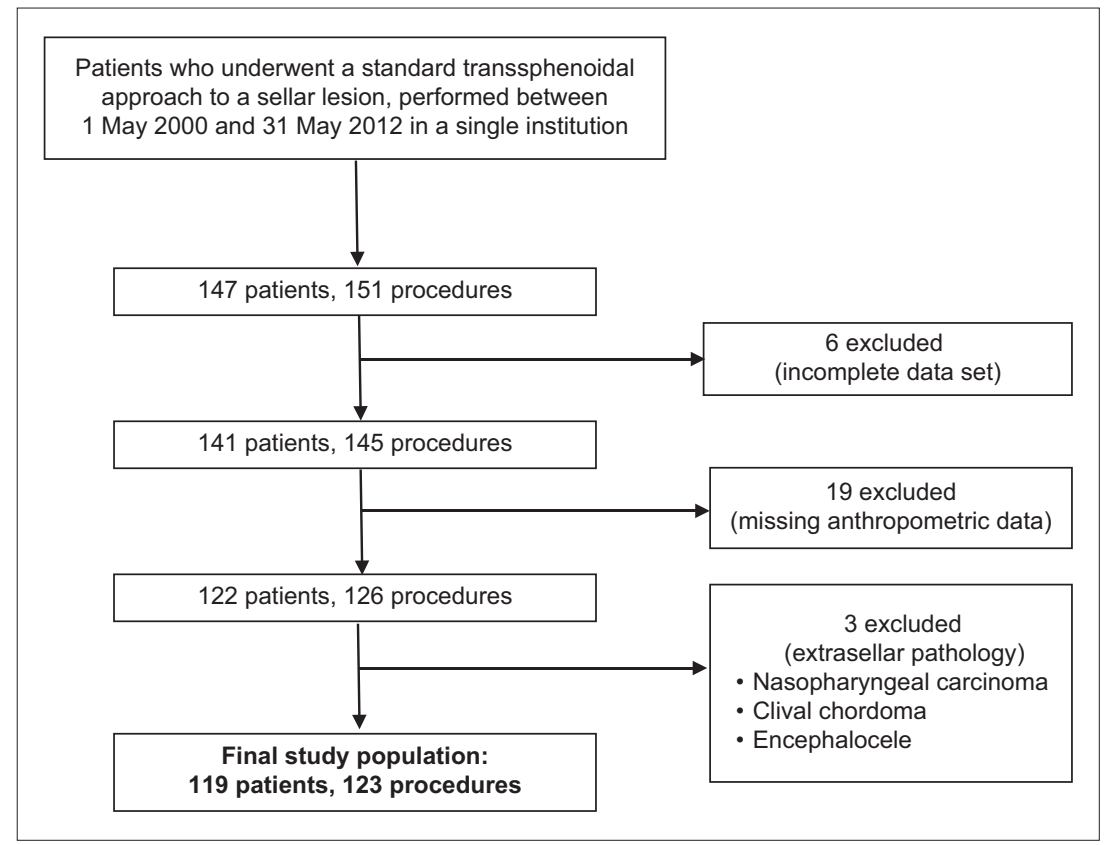

Fig. 1 Flowchart shows the inclusion and exclusion criteria used for patient selection.

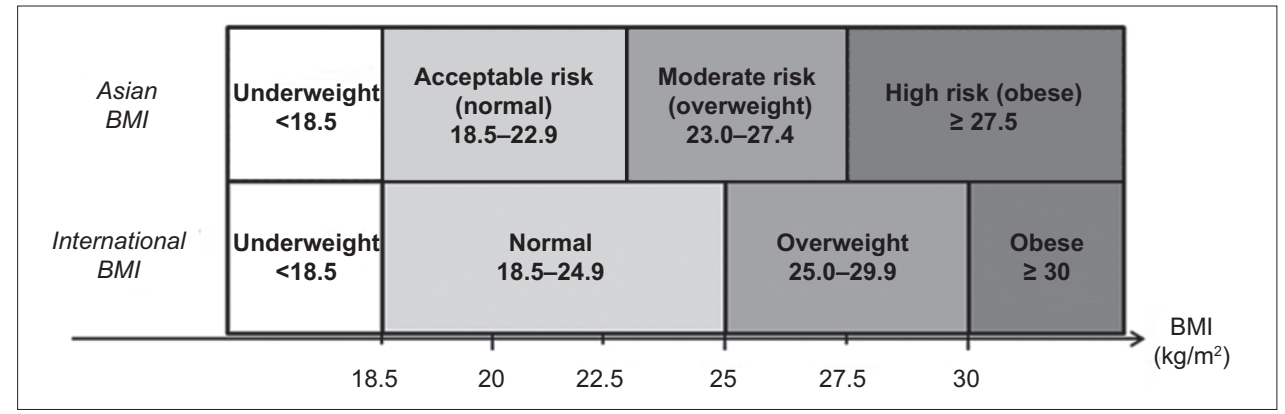

Fig. 2 Chart shows differences in threshold between the World Health Organization's international and Asian body mass index (BMI) classifications.

sublabial - but all procedures were performed using a standard transsphenoidal approach (i.e. none of the procedures had expanded approaches). Various combinations of autologous and non-autologous grafts were used for the repair or reconstruction of the sellar floor. This included fascia lata, fat, remnant bone from the sellar opening and equine collagen biomatrix (TissuDura ${ }^{\circledR}$,

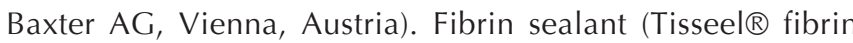
sealant; Baxter Healthcare, Deerfield, IL, USA) was commonly used as reinforcement. For some endonasal procedures, the use of a vascularised nasoseptal mucosal flap was also an option. All except 18 procedures were performed using an operating microscope. For 18 transsphenoidal surgeries, visualisation was aided by the use of an endoscope via a transnasal approach, with assistance from an otorhinolaryngologist.

Patients were divided into two groups based on the presence or absence of postoperative CSF leak. Wilcoxon rank-sum and Fisher's exact tests were used to compare these patient groups for continuous and dichotomous variables, respectively. Factors such as ethnicity, BMI, the use of endoscope, intraoperative CSF leak, repeat procedures and methods of sellar repair were examined in a series of univariate analyses. Multivariate regression analysis based on a stepwise approach was also performed, including univariate analyses with $p<0.20$ as the cut-off for inclusion in the final adjusted model. Statistical analysis of the data was performed using IBM SPSS Statistics version 20 (IBM Corp, Armonk, NY, USA). A p-value $<0.05$ was considered as statistically significant.

\section{RESULTS}

A total of 123 transsphenoidal surgeries for sellar repair were performed for 119 patients, among which 59 (48.0\%) procedures were performed on men (Table I). The median age of the patients during surgery was 47 (range 13-89) years. A majority of the procedures $(76.4 \%)$ were performed on patients of Chinese ethnicity, consistent with Singapore's population, which is predominantly Chinese.

Pituitary adenoma (89.4\%) was the most common histopathological diagnosis noted in our study, accounting for nearly nine in every ten procedures (Table II). Six patients underwent repeat procedures, which was defined as surgery on a patient who had undergone a previous similar procedure within any period of time, but not within the same admission and without clinical evidence of CSF leak prior to the reviewed surgical procedure.

$10(8.1 \%)$ procedures in ten patients were complicated by postoperative CSF leak. The closure technique varied in this group, with different combinations of materials used for the 
Table I. Demographic details of patients who underwent transsphenoidal procedures $(n=123)$.

\begin{tabular}{|c|c|}
\hline Variable & No. (\%) \\
\hline Age $(y r)^{*}$ & $47(13-89)$ \\
\hline BMI $\left(\mathrm{kg} / \mathrm{m}^{2}\right)^{*}$ & $24.9(17.8-46.3)$ \\
\hline Male gender & $59(48.0)$ \\
\hline \multicolumn{2}{|l|}{ Ethnicity } \\
\hline Chinese & $94(76.4)$ \\
\hline Malay & $9(7.3)$ \\
\hline Indian & $8(6.5)$ \\
\hline Other & $12(9.8)$ \\
\hline \multicolumn{2}{|l|}{ International BMI category } \\
\hline Underweight & $3(2.4)$ \\
\hline Normal & $59(48.0)$ \\
\hline Overweight & $37(30.1)$ \\
\hline Obese & $24(19.5)$ \\
\hline \multicolumn{2}{|l|}{ Asian BMI category } \\
\hline Underweight & $3(2.4)$ \\
\hline Low risk & $35(28.5)$ \\
\hline Moderate risk & $48(39.0)$ \\
\hline High risk & $37(30.1)$ \\
\hline \multicolumn{2}{|l|}{ Approach } \\
\hline Sublabial & $70(56.9)$ \\
\hline Transnasal & $53(43.1)$ \\
\hline \multicolumn{2}{|l|}{ Perioperative } \\
\hline Intraoperative CSF leak & $21(17.1)$ \\
\hline Repeat procedure & $6(4.9)$ \\
\hline Endoscope assisted & $18(14.6)$ \\
\hline Use of autologous materials for repair & $63(51.2)$ \\
\hline Use of mucosal flap for repair & $7(5.7)$ \\
\hline \multicolumn{2}{|l|}{ Postoperative } \\
\hline 30-day mortality & $1(0.8)$ \\
\hline Postoperative CSF leak & $10(8.1)$ \\
\hline
\end{tabular}

*Data presented as median (range). BMI: body mass index; CSF: cerebrospinal fluid

reconstruction and repair of the sellar floor (Table III). Two of the ten patients required reparative surgery, while the remaining eight patients were successfully managed using measures such as bed rest in a flat supine position, repeated lumbar punctures or insertion of a lumbar drain.

$1(0.8 \%)$ patient died on the 20th postoperative day due to intracranial bleeding at the operative site complicated by hydrocephalus and cerebral infarction, which did not improve despite ventriculostomy. Another patient $(0.8 \%)$ developed postoperative meningitis, which occurred despite the absence of postoperative CSF leakage. She was successfully treated using intravenous antibiotics.

No significant difference was noted between patients with and without postoperative CSF leak with regard to gender, age and ethnicity (Table IV). The median BMI of patients with postoperative leak was significantly greater than that of patients without postoperative leak $\left(27.0 \mathrm{~kg} / \mathrm{m}^{2} \mathrm{vs} .24 .6 \mathrm{~kg} / \mathrm{m}^{2}\right.$; $p=0.018)$. There was a trend toward increased occurrence of postoperative leak with increasing obesity, which was
Table II. Histopathological diagnoses of patients who underwent transsphenoidal procedures $(n=123)$.

\begin{tabular}{|ll|}
\hline Diagnosis & No. (\%) \\
\hline Pituitary adenoma & $110(89.4)$ \\
\hline Rathke's cleft cyst & $7(5.7)$ \\
\hline Craniopharyngioma & $1(0.8)$ \\
\hline Carcinoma & $1(0.8)$ \\
\hline Germinoma & $1(0.8)$ \\
\hline Other & \\
\hline Fibrous tissue & - \\
\hline Reactive purulent tissue & $3(2.4)$ \\
\hline Haematoma & - \\
\hline
\end{tabular}

Table III. Types of material used for sellar floor reconstruction in patients with postoperative CSF leak $(n=10)$.

\begin{tabular}{|c|c|c|c|}
\hline \multirow[t]{2}{*}{ Patient } & \multicolumn{2}{|c|}{ Material used } & \multirow{2}{*}{$\begin{array}{l}\text { Tisseel }{ }^{\circledR} \\
\text { fibrin glue }\end{array}$} \\
\hline & Autologous (TFL, fat) & Non-autologous & \\
\hline 1 & TFL, fat & - & Yes \\
\hline 2 & TFL, fat & - & Yes \\
\hline 3 & - & Surgicel ${ }^{\circledR}$ & Yes \\
\hline 4 & - & - & - \\
\hline 5 & TFL & - & - \\
\hline 6 & Fat & - & Yes \\
\hline 7 & - & Surgicel ${ }^{\circledR}$ & Yes \\
\hline 8 & - & - & Yes \\
\hline 9 & TFL & - & Yes \\
\hline 10 & TFL, fat & - & Yes \\
\hline
\end{tabular}

For Patient 4, nasal packs were placed without further sellar floor reconstruction; no intraoperative leak was noted. CSF: cerebrospinal fluid; TFL: tensor fascia lata

observed when patients were categorised using both the WHO international ( $p=0.192)$ and Asian BMI $(p=0.176)$ classifications. This association was more pronounced when compared using the well-established three-tiered classification (international: $p=0.096$; Asian: $p=0.084$ ), although it did not reach statistical significance. None of the patients classified as acceptable under the Asian BMI three-tiered classification developed postoperative CSF leak (Fig. 3). When stratified using the two-tiered Asian BMI classification, we found that all patients who had postoperative CSF leak were of at least moderate risk (100.0\%). Among patients who did not develop postoperative leak, this percentage was lower, with only about two-thirds $(66.4 \%)$ being categorised as moderate and high risk; this difference in the proportion of moderate- and highrisk procedures among patients with and without postoperative CSF leak was found to be statistically significant ( $p=0.030)$.

Repeat procedures were found to be associated with increased risk of postoperative CSF leak on univariate analysis ( $p=0.041$; Table V). The occurrence of intraoperative leak $(p=0.268)$, use of endoscope $(p=0.668)$, transnasal approach $(p=0.389)$ and the use of autologous materials for repair or reconstruction of the sellar floor $(p=0.564)$ were all not statistically significant on univariate analysis in relation to the occurrence of postoperative CSF leak following transsphenoidal procedures (data not shown). 
Table IV. Demographic data of patients stratified by the presence or absence of a postoperative CSF leak.

\begin{tabular}{|c|c|c|c|}
\hline \multirow[t]{2}{*}{ Variable } & \multicolumn{2}{|c|}{ No. (\%) } & \multirow[t]{2}{*}{ p-value } \\
\hline & $\begin{array}{l}\text { No postoperative CSF leak } \\
(n=113)\end{array}$ & $\begin{array}{l}\text { Postoperative CSF leak } \\
(n=10)\end{array}$ & \\
\hline Age $(y r)^{*}$ & $47.0(13-89)$ & $48.0(19-65)$ & 0.518 \\
\hline BMI $\left(\mathrm{kg} / \mathrm{m}^{2}\right)^{*}$ & $24.6(17.8-46.3)$ & $27.0(23.6-39.4)$ & $0.018+$ \\
\hline Male gender & $55(48.7)$ & $4(40.0)$ & 0.746 \\
\hline Ethnicity (dichotomised) & & & 0.244 \\
\hline Chinese & $88(77.9)$ & $6(60.0)$ & \\
\hline Other & $25(22.1)$ & $4(40.0)$ & \\
\hline International BMI category & & & 0.192 \\
\hline Underweight & $3(2.7)$ & $0(0)$ & \\
\hline Normal & $57(50.4)$ & $2(20.0)$ & \\
\hline Overweight & $33(29.2)$ & $4(40.0)$ & \\
\hline Obese & $20(17.7)$ & $4(40.0)$ & \\
\hline Asian BMI category & & & 0.176 \\
\hline Underweight & $3(2.7)$ & $0(0)$ & \\
\hline Low risk & $35(31.0)$ & $0(0)$ & \\
\hline Moderate risk & $42(37.2)$ & $6(60.0)$ & \\
\hline High risk & $33(29.2)$ & $4(40.0)$ & \\
\hline Three-tiered international BMI & & & 0.096 \\
\hline Acceptable & $60(53.1)$ & $2(20.0)$ & \\
\hline Overweight & $33(29.2)$ & $4(40.0)$ & \\
\hline Obese & $20(17.7)$ & $4(40.0)$ & \\
\hline Three-tiered Asian BMI & & & 0.084 \\
\hline Acceptable & $38(33.6)$ & $0(0)$ & \\
\hline Moderate risk & $42(37.2)$ & $6(60.0)$ & \\
\hline High risk & $33(29.2)$ & $4(40.0)$ & \\
\hline Two-tiered international BMI & & & 0.054 \\
\hline Underweight and normal & $60(53.1)$ & $2(20.0)$ & \\
\hline Overweight and obese & $53(46.9)$ & $8(80.0)$ & \\
\hline Two-tiered Asian BMI & & & $0.030^{+}$ \\
\hline Underweight and low risk & $38(33.6)$ & $0(0)$ & \\
\hline Moderate and high risk & $75(66.4)$ & $10(100.0)$ & \\
\hline \multicolumn{4}{|l|}{ Perioperative } \\
\hline Intraoperative CSF leak & $18(15.9)$ & $3(30.0)$ & 0.372 \\
\hline Repeat procedure & $4(3.5)$ & $2(20.0)$ & 0.075 \\
\hline Endoscope assisted & $17(15.0)$ & $1(10.0)$ & 1.000 \\
\hline Use of autologous materials for repair & $57(50.4)$ & $6(60.0)$ & 0.744 \\
\hline Use of mucosal flap for repair & $7(6.2)$ & $0(0)$ & 1.000 \\
\hline Nasal approach & $50(44.2)$ & $3(30.0)$ & 0.513 \\
\hline
\end{tabular}

*Data presented as median (range). ${ }^{+p}<0.05$ was considered statistically significant. BMI: body mass index; CSF: cerebrospinal fluid

\section{DISCUSSION}

The transsphenoidal approach to lesions in the sella turcica has seen many advances throughout the last century. Hirsch and Cushing were pioneers of the technique in the early 1900s, ${ }^{(6)}$ and Hardy was credited with popularising the technique again in the 1960s with the use of the operating microscope and the advent of antibiotics, ${ }^{(7)}$ reducing complication rates arising from CSF leak and meningitis, which had plagued this procedure a few decades earlier. More recently, the use of endoscopes, which was popularised in the 1990 s by Carrau et $\mathrm{al}^{\left({ }^{(8)}\right.}$ is playing an increasingly important role in current practice, offering superior visualisation compared to the traditional microscope. Despite these advances, the risk of postoperative CSF leak following transsphenoidal surgeries remains a significant complication with potentially severe morbidity and mortality, particularly for infection in the form of meningitis.

Obesity is a major cause of morbidity and mortality in developed countries, including Singapore. The WHO introduced an international classification for obesity in 1995, which was termed as BMI. ${ }^{(9)}$ The year 2004 saw the introduction of a specific BMI range for determining public health and clinical action in Asian populations, in recognition of the health risks posed at lower BMI values in this population. ${ }^{(10)}$ Data from the latest National Health Survey revealed that $23.0 \%$ of Singaporean adults were in 

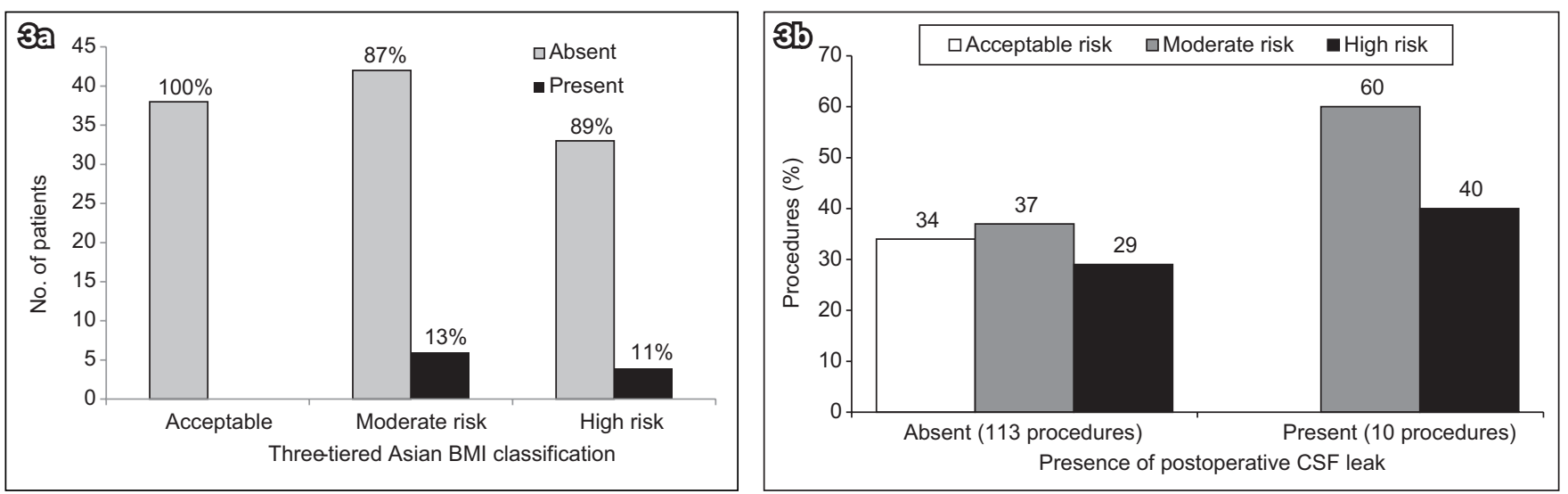

Fig. 3 Charts show (a) the occurrence of postoperative CSF leak stratified by the three-tiered Asian BMI classification, and (b) the association between Asian BMI categories and the occurrence of postoperative CSF leak. BMI: body mass index; CSF: cerebrospinal fluid

Table V. Univariate and multivariate analysis of risk factors for postoperative CSF leak.

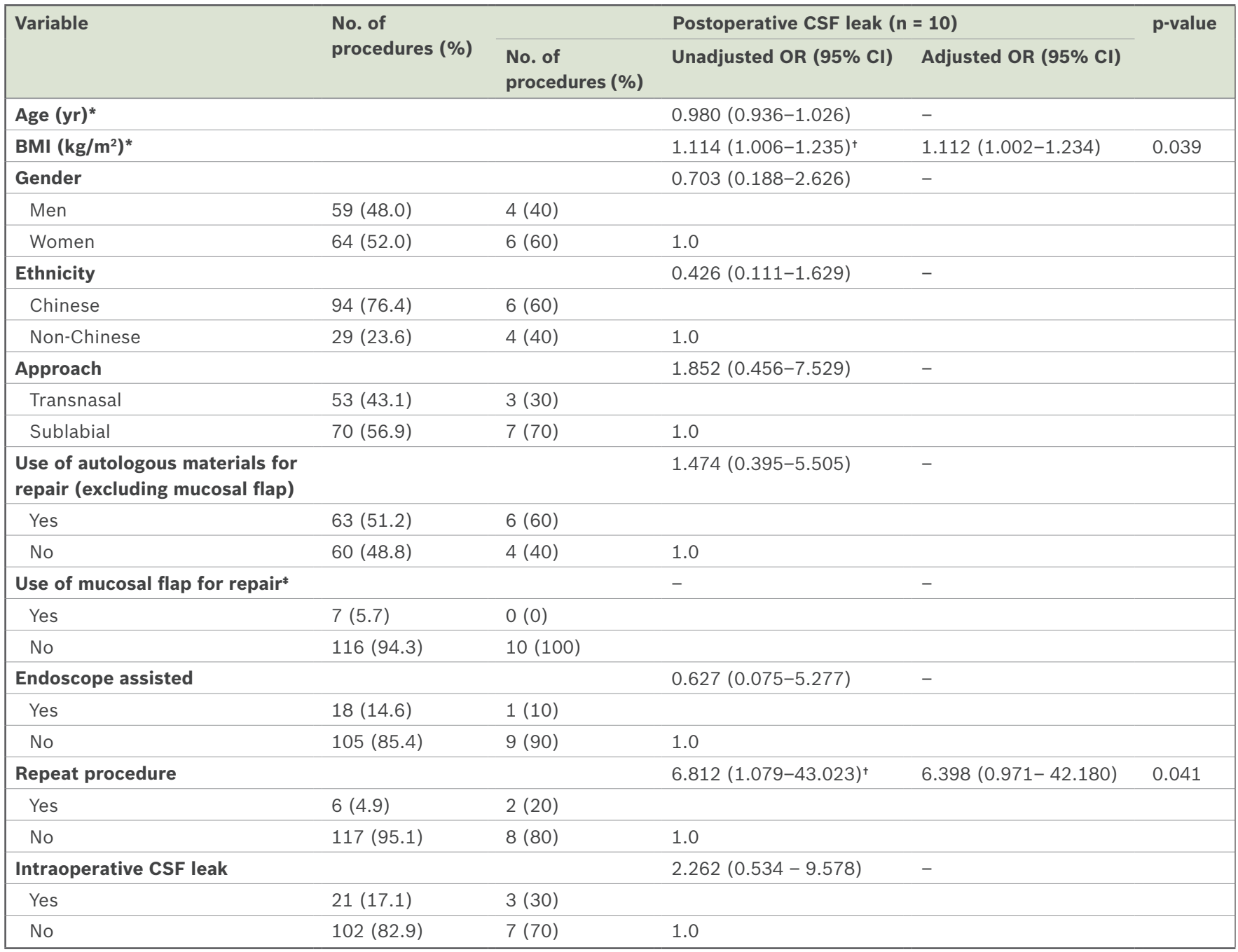

*Wilcoxon rank-sum test was used for continuous variable calculations. †Association was statistically significant on univariate analysis. $¥$ None of the seven patients for whom mucosal flaps were used had postoperative CSF leak. BMI: body mass index; CI: confidence interval; CSF: cerebrospinal fluid; OR: odds ratio

the high-risk group under the Asian BMI classification. Moreover, the trend of obesity in Singapore has been increasing steadily, with age-standardised prevalence rising from $6.3 \%$ in 1998 to $10.8 \%$ in 2010 . $^{(11)}$

Obesity is purported to be a significant risk factor for the occurrence of spontaneous CSF rhinorrhoea. ${ }^{(12-14)}$ It has also been linked to raised intracranial pressure in various metabolic ${ }^{(15-17)}$ and mechanical theories, ${ }^{(18,19)}$ and is a recognised risk factor in the setting of idiopathic intracranial hypertension. ${ }^{(15,20)}$ More recently, observations by Dlouhy et $\mathrm{al}^{\left({ }^{(4)}\right.}$ and Ivan et $\mathrm{a}^{\left({ }^{(5)}\right.}$ have suggested an association between obesity and increased risk of postoperative CSF leak following transnasal anterior skull base approaches. The exact 
pathophysiology is uncertain, but it is likely that the associations between elevated BMI and spontaneous CSF leak and between obesity and intracranial hypertension share a similar pathogenesis, with sustained elevated intracranial pressure eventually resulting in dehiscence of the sellar reconstruction following surgery. ${ }^{(4)}$

We found a significantly higher median BMI among patients with postoperative CSF leak following transsphenoidal procedures, compared with those without. Notably, this result, while consistent with that of Dlouhy et al, is from a multiracial Asian population. Our rate of postoperative CSF leak (8.1\%) was lower than the $13.5 \%$ reported in the earlier study. This may be partly attributed to the lower median BMI observed in our Asian study population (BMI $27.0 \mathrm{~kg} / \mathrm{m}^{2}$ ) as opposed to the North American population in Dlouhy et al's study (BMI $\left.39.2 \mathrm{~kg} / \mathrm{m}^{2}\right)^{(4)}$

Repeat procedures were found to be associated with an increased risk of postoperative CSF leak. This was not unexpected given the obvious difficulties resulting from the alterations in anatomy and surgical planes following the initial surgery, and the subsequent increased risk of intraoperative leak. Contrary to the findings by Ivan et al, ${ }^{(5)}$ we did not find a significant relationship between the occurrences of intraoperative and postoperative leaks. This observation could have been due to unintentional bias when operating surgeons made greater efforts to ensure a good repair following an intraoperative leak. Given the small number of patients in the present study, however, the strength of correlations drawn between BMI and postoperative CSF leak following transsphenoidal procedures remains weak. Our study results should thus be interpreted with caution.

Various techniques have been described with regard to sellar reconstruction following a transsphenoidal approach, differing in the type of materials used and the manner in which they are utilised (e.g. tiered or combination repairs). ${ }^{(21,22)}$ Reconstruction methods varied widely in our study due to the number of surgeons involved. The usage of autologous materials in the form of fascia lata or fat was analysed, given its historical importance as the earliest effective method of sellar reconstruction, as described by Dandy ${ }^{(23)}$ and Collins, ${ }^{(24)}$ but no significant correlation was found with respect to postoperative CSF leak.

The vascularised nasoseptal flap, first described by Hadad et al, ${ }^{(25)}$ has become increasingly popular, with recent literature suggesting that its use could reduce the incidence of postoperative CSF leak when compared to mucosal-free grafts. ${ }^{(3,26,27)}$ Our study included only a small proportion (5.7\%) of patients who had undergone a nasoseptal flap repair. Although none of these patients developed postoperative CSF leaks, the small sample size limits us from making any firm inferences regarding its usefulness in reducing the occurrence of postoperative CSF leak subsequent to transsphenoidal procedures among patients with elevated BMI. Given what we understand from the current literature, however, it would be reasonable to consider the use of such flap repair, in conjunction with meticulous surgical technique, in order to minimise the risk of postoperative CSF leak in higher-risk patients, such as those with elevated BMI.

To the best of our knowledge, this is the largest study to consider the relationship between elevated $\mathrm{BMI}$ and the occurrence of postoperative CSF leak following transsphenoidal procedures - an association that has only been described in recent years and in just two previous articles. Furthermore, this is the only study that has specifically focused on an Asian population while considering region-specific criteria for BMI.

This study was not without limitations. We acknowledge the inherent bias that is associated with any retrospective method of data retrieval and analysis. Other limitations, such as the heterogeneity of the lesional pathology, surgical approach, and the technique and method of sellar reconstruction, may also dilute the strength of any potential correlation drawn between $\mathrm{BMI}$ and the incidence of postoperative CSF leak in these patients. Given the relatively low incidence of this complication, a larger sample size would help to increase the overall power of the study, including correlations between CSF leak and other risk factors during subgroup analysis.

In conclusion, elevated BMI has been shown to be a significant predictor for postoperative CSF leak following transsphenoidal surgery. This holds true even in an Asian population when regionspecific BMI measures are applied, showing the strength of this association across diverse populations. Larger prospective studies are warranted to further validate this relationship.

\section{ACKNOWLEDGEMENT}

The authors would like to thank Ms San Moe Thu, Department of Surgery, NUS Yong Loo Lin School of Medicine, National University of Singapore, Singapore, for her role in facilitating the statistical analysis. This work was presented as a poster at the ASEAN (Association of Southeast Asian Nations) Neuroscience 2015 meeting held in Singapore in July 2015.

\section{REFERENCES}

1. Senior BA, Ebert CS, Bednarski KK, et al. Minimally invasive pituitary surgery. Laryngoscope 2008; 118:1842-55.

2. Zhan R, Chen S, Xu S, Liu JK, Li X. Postoperative low-flow cerebrospinal fluid leak of endoscopic endonasal transsphenoidal surgery for pituitary adenoma-wait and see, or lumbar drain? J Craniofac Surg 2015; 26:1261-4.

3. Kassam AB, Prevedello DM, Carrau RL, et al. Endoscopic endonasal skull base surgery: analysis of complications in the authors' initial 800 patients. J Neurosurg $2011 ; 114: 1544-68$.

4. Dlouhy BJ, Madhavan K, Clinger JD, et al. Elevated body mass index and risk of postoperative CSF leak following transsphenoidal surgery. J Neurosurg 2012; 116:1311-7.

5. Ivan ME, Iorgulescu JB, El-Sayed I, et al. Risk factors for postoperative cerebrospinal fluid leak and meningitis after expanded endoscopic endonasal surgery. J Clin Neurosci 2015; 22:48-54.

6. Lanzino G, Laws ER Jr. Pioneers in the development of transsphenoidal surgery: Theodor Kocher, Oskar Hirsch, and Norman Dott. J Neurosurg 2001; 95:1097-103.

7. Liu JK, Das K, Weiss MH, Laws ER Jr, Couldwell WT. The history and evolution of transsphenoidal surgery. J Neurosurg 2001; 95:1083-96.

8. Carrau RL, Jho HD, Ko Y. Transnasal-transsphenoidal endoscopic surgery of the pituitary gland. Laryngoscope 1996; 106:914-8.

9. World Health Organization. Physical status: the use and interpretation of anthropometry. Report of a WHO Expert Committee. WHO Technical Report Series 854. Geneva: World Health Organization, 1995.

10. WHO Expert Consultation. Appropriate body-mass index for Asian populations and its implications for policy and intervention strategies. Lancet 2004; 363:157-63.

11. Ministry of Health, Singapore. National Health Survey 2010. Available at: https://www.moh.gov.sg/content/moh_web/home/Publications/Reports/2011/ national_health_survey2010.html. Accessed January 31, 2016.

12. Lindstrom DR, Toohill RJ, Loehrl TA, Smith TL. Management of cerebrospinal fluid rhinorrhea: the Medical College of Wisconsin experience. Laryngoscope 2004; 114:969-74. 
13. Dunn CJ, Alaani A, Johnson AP. Study on spontaneous cerebrospinal fluid rhinorrhoea: its aetiology and management. J Laryngol Otol 2005; 119:12-5.

14. Banks CA, Palmer JN, Chiu AG, et al. Endoscopic closure of CSF rhinorrhea: 193 cases over 21 years. Otolaryngol Head Neck Surg 2009; 140:826-33.

15. Ooi LY, Walker BR, Bodkin PA, Whittle IR. Idiopathic intracranial hypertension: can studies of obesity provide the key to understanding pathogenesis? $\mathrm{Br}$ Neurosurg 2008; 22:187-94.

16. Abdollahi M, Cushman M, Rosendaal FR. Obesity: risk of venous thrombosis and the interaction with coagulation factor levels and oral contraceptive use. Thromb Haemost 2003; 89:493-8.

17. Lampl Y, Eshel Y, Kessler A, et al. Serum leptin level in women with idiopathic intracranial hypertension. I Neurol Neurosurg Psychiatry 2002; 72:642-3.

18. Sugerman HJ, DeMaria EJ, Felton WL 3rd, Nakatsuka M, Sismanis A. Increased intra-abdominal pressure and cardiac filling pressures in obesity-associated pseudotumor cerebri. Neurology 1997; 49:507-11.

19. Sugerman HJ, Felton WL 3rd, Sismanis A, et al. Gastric surgery for pseudotumor cerebri associated with severe obesity. Ann Surg 1999; 229:634-40; discussion 640-2.

20. Sugerman HJ, Felton WL 3rd, Salvant JB Jr, Sismanis A, Kellum JM. Effects of surgically induced weight loss on idiopathic intracranial hypertension in morbid obesity. Neurology 1995; 45:1655-9.

21. Cappabianca P, Cavallo LM, Esposito F, Valente V, De Divitiis E. Sellar repair in endoscopic endonasal transsphenoidal surgery: results of 170 cases. Neurosurgery 2002; 51:1365-71; discussion 1371-2.

22. Couldwell WT, Kan P, Weiss MH. Simple closure following transsphenoidal surgery. Technical note. Neurosurg Focus 2006; 20:E11.

23. Dandy WE. Pneumocephalus (intracranial pneumatocele or aerocele). Arch Surg 1926; 12:949-82.

24. Collins WF. Hypophysectomy: historical and personal perspective. Clin Neurosurg 1974; 21:68-78.

25. Hadad G, Bassagasteguy L, Carrau R, et al. A novel reconstructive technique after endoscopic expanded endonasal approaches: vascular pedicle nasoseptal flap. Laryngoscope 2006; 116:1882-6.

26. McCoul ED, Anand VK, Singh A, et al. Long-term effectiveness of a reconstructive protocol using a nasoseptal flap after endoscopic skull base surgery. World Neurosurg 2014; 81:136-43.

27. Park JH, Choi JH, Kim YI, Kim SW, Hong YK. Modified Graded Repair of Cerebrospinal Fluid Leaks in Endoscopic Endonasal Transsphenoidal Surgery. J Korean Neurosurg Soc 2015; 58:36-42. 